\title{
ANALISIS FAKTOR-FAKTOR YANG MEMPENGARUHI PRODUKSI SUSU KAMBING PERAH PERANAKAN ETAWA (PE) DI DESA LIMPOK KECAMATAN DARUSSALAM KABUPATEN ACEH BESAR (STUDI KASUS DI UD. ATJEH LIVESTOCK FARM)
}

(Analysis of the Factors Affecting the Production of Goat Milk Dairy Crossbreed Etawa (PE) in The Limpok Village Sub-Districts of Darussalam Aceh Besar Regency A Case Study in UD. Atjeh Livestock Farm)

\author{
Rini Afrida ${ }^{1}$, Suyanti Kasimin ${ }^{1}$, Edy Marsudi ${ }^{1 *}$ \\ ${ }^{1}$ Program Studi Agribisnis, Fakultas Pertanian, Universitas Syiah Kuala
}

\begin{abstract}
Abstrak - Susu kambing perah merupakan komoditas yang cukup penting di Indonesia. Penelitian ini bertujuan untuk Menganalisis pengaruh jumlah pemberian pakan hijauan dan ampas tahu terhadap produksi susu kambing perah di UD. Atjeh Livestock Farm yang berada di Desa Limpok Kecamatan Darussalam Kabupaten Aceh Besar. Metode penelitian yang digunakan adalah metode studi kasus dengan objek penelitian seluruh kambing perah peranakan etawa (PE) yang memproduksi susu di UD. Atjeh Livestock Farm. Metode analisis yang digunakan dalam penelitian ini adalah Model Cobb Douglas. Hasil penelitian menunjukkan bahwa variabel jumlah pakan hijauan dan ampas tahu mempunyai pengaruh nyata baik secara serempak maupun parsial terhadap produksi susu, dimana diperoleh nilai dari uji serempak untuk $F_{\text {hit }}=138.415$ sedangkan untuk $F_{\text {tabel }}=3.98$, karena nilai $F_{\text {hit }}=$ $138.415>\mathrm{F}_{\text {tabel }}=3.98$, maka kesimpulan yang dapat diambil adalah menolak $\mathrm{H}_{0}$. Artinya variabel hijauan dan ampas tahu secara bersama - sama mempunyai pengaruh nyata terhadap produksi susu kambing perah, sedangkan dari uji parsial diperoleh nilai variabel hijauan untuk $t_{\text {hitung }}=4,016$ sedangkan $t_{\text {tabelnya }}=2,17881$, karena nilai $t_{\text {hitung }}=4,016>t_{\text {tabel }}=2,17881$, maka kesimpulan yang dapat diambil adalah menolak $\mathrm{H}_{0}$. Begitu juga untuk variabel ampas tahu diperoleh nilai untuk $t_{\text {hitung }}=2,255$ sedangkan $t_{\text {tabelnya }}=2,17881$, karena nilai $t_{\text {hitung }}=$ $2,255>\mathrm{t}_{\text {tabel }}=2,17881$, maka kesimpulan yang dapat diambil adalah menolak $\mathrm{H}_{0}$. Artinya variabel hijauan maupun ampas tahu mempunyai pengaruh nyata terhadap produksi susu kambing perah.
\end{abstract}

Kata Kunci: Produksi Susu , Hijauan dan Ampas Tahu

\begin{abstract}
Dairy goat milk is a commodity that is quite important in Indonesia. This study aimed to analyze the influence of the number of feeding forage and pulp out of the milk production of dairy goats in UD. Atjeh Livestock Farm that are in the Limpok village subdistrict of Darussalam Aceh Besar regency. The method used is the case study method with the object of study throughout the dairy goat hybrid etawa (PE), which produces milk in UD. Atjeh Livestock Farm. The analytical method used in this study is a model Cobb Douglas. The results showed that the variable amount of green feed and tofu has a real influence both simultaneously and partially to the production of milk, which gained the value of simultaneous test for $\mathrm{F}_{\text {count }}=138.415$ whereas for $\mathrm{F}_{\text {table }}=3.98$, because the value $\mathrm{F}_{\text {count }}=$ $138.415>\mathrm{F}_{\text {table }}=3.98$, the conclusions that can be drawn is to reject $\mathrm{H}_{0}$. This means that the variable forages and pulp out together have a significant effect on the milk production of dairy goats, whereas the values obtained from the partial test variable forage for $t_{\text {count }}=4,016$ whereas $t_{\text {table }}=2,17881$, because the value of $t_{\text {count }}=4,016>t_{\text {table }}=2,17881$, the conclusions that can be drawn is to reject $\mathrm{H}_{0}$. Likewise for variable pulp out obtained value for $\mathrm{t}_{\text {count }}=$
\end{abstract}


2,255 whereas $t_{\text {table }}=2,17881$, because the value of $t_{\text {count }}=2,255>t_{\text {table }}=2,17881$, the conclusions that can be drawn is to reject $\mathrm{H}_{0}$. This means that the variable forage or pulp out has a significant effect on the milk production of dairy goats.

Keywords: Milk Production, Forage and Pulp Out

\section{PENDAHULUAN}

Pembangunan Subsektor Peternakan di Indonesia merupakan bagian yang tidak terpisahkan dalam pembangunan pertanian yang mengacu pada pembangunan perekonomian Indonesia secara keseluruhan. Pada hakekatnya pembangunan ekonomi bertujuan untuk meningkatkan taraf hidup masyarakat, memperbesar lapangan pekerjaan, meningkatkan dan pemerataan pendapatan masyarakat. Hal ini menunjukkan bahwa setiap kegiatan usaha peternakan memiliki tanggung jawab untuk menyertakan tujuan kemanusiaan, kesejahteraan rakyat dan kelestarian sumberdaya alam bersama dengan tujuan usaha itu sendiri dalam mengejar keuntungan dan perkembangan (Sirait, 2009).

Aceh termasuk dalam salah satu sentra peternakan kambing di Indonesia. Meskipun populasi ternak kambing di Aceh setiap tahunnya berfluktuasi namun peranan dan potensi peternakan kambing di Aceh masih sangat besar dalam perekonomian daerah yang dijelaskan pada tabel di bawah ini:

Tabel 1. Populasi Ternak Kambing Aceh 2010-2014 (Ekor)

\begin{tabular}{|c|c|c|c|}
\hline No & Tahun & Jumlah Populasi Ternak (ekor) & pertumbuhan (\%) \\
\hline 1 & 2010 & 8.448 & 25,5 \\
\hline 2 & 2011 & 5.568 & 16,7 \\
\hline 3 & 2012 & 5.817 & 17,5 \\
\hline 4 & 2013 & 6.567 & 19,8 \\
\hline 5 & 2014 & 6.794 & 20,6 \\
\hline
\end{tabular}

Sumber : Direktorat jenderal Peternakan dan Kesehatan hewan, 2014

Pada umumnya fluktuasi populasi ternak kambing di Aceh yang disebabkan oleh sistem dan cara beternak masyarakat yang masih tradisional, dimana mereka cenderung menjual ternak kambing mereka pada saat mengalami kesulitan dalam keuangan. Salah satu usaha ternak yang berpotensi di Aceh adalah peternakan kambing etawa. Peternakan kambing etawa ini lebih mengutamakan hasil produksi kambing berupa susu segar. Sesuai dengan hasil penelitian bahwa jenis kambing etawa adalah jenis kambing yang diusahakan untuk diambil susunya (Janri Wolden H. S, 2009). Hal ini mengindikasikan bahwa masyarakat lebih mengutamakan peternakan kambing perah yang mengutamakan produksi susu daripada beternak kambing yang hanya untuk mendapatkan daging.

UD. Atjeh Livestock Farm merupakan pengembangan usaha peternakan kambing perah skala komersil yang mempertimbangkan faktor sosial ekonomi, letak atau lokasi peternakan juga berjauhan dengan pemukiman warga, sehingga penduduk di sekitar peternakan tidak merasa terganggu dengan bau kotoran dari ternak tersebut. Permintaan konsumen akan produk susu merupakan peluang yang harus dimanfaatkan oleh pemilik peternakan kambing perah di UD. Atjeh Livestock Farm, Namun Sampai dengan saat ini perusahaan masih 
dihadapkan dengan masalah yang berasal dari produksi susu kambing yang rendah, Produksi susu rata-rata kambing yang dipelihara peternak masih tergolong rendah yaitu sekitar 0,5 - 1 liter per ekor per hari, sedangkan produksi ideal seharusnya dapat mencapai 3 liter per hari (Setiawan dan Tanius, 2005).

Rendahnya produksi susu kambing, perah dipengaruhi oleh faktor Teknis antara lain faktor pemberian pakan hijauan dan ampas tahu Maka dari itu, perlu upaya untuk meningkatkan produksi susu di UD. Atjeh Livestock Farm dengan menganalisis faktorfaktor apa yang berpengaruh terhadap produksi susu agar penerimaan peternak dari hasil penjualan susu dapat meningkat.

Adapun tujuan penelitian adalah untuk menganalisis pengaruh jumlah pemberian pakan hijauan dan ampas tahu terhadap produksi susu kambing perah di UD. Atjeh Livestock Farm di Desa Limpok Kecamatan Darussalam Kabupaten Aceh Besar.

\section{METODE PENELITIAN}

Penelitian ini dilakukan di peternakan kambing perah UD. Atjeh Livestock Farm di Desa Limpok, Kecamatan Darussalam, Kabupaten Aceh Besar. Penentuan daerah penelitian dilakukan secara sengaja (Purposive Sampling) dengan pertimbangan bahwa daerah tersebut merupakan tempat peternakan kambing perah UD. Atjeh Livestock Farm yang saat ini sedang melakukan pengembangan usaha kambing perah. Objek penelitian ini adalah ternak kambing perah yang memproduksi susu di UD. Atjeh Livestock Farm. Ruang lingkup penelitian terbatas pada faktor- faktor teknis yaitu jumlah pemberian pakan hijauan dan jumlah pemberian ampas tahu yang mempengaruhi produksi susu kambing di UD. Atjeh Livestock Farm di Desa Limpok, Kecamatan Darussalam, Kabupaten Aceh Besar.

Metode yang digunakan dalam penelitian ini adalah metode studi kasus (case study) dengan pengamatan langsung di lapangan. Pada peternakan UD. Atjeh Livestock Farm objek yang diambil berjumlah 15 (lima belas) ekor kambing, yaitu seluruh kambing yang memproduksi susu. Data yang digunakan dalam penelitian ini adalah data primer dan data sekunder. Data primer diperoleh melalui pengamatan langsung di lapangan dan wawancara dengan peternak kambing perah. Sedangkan data sekunder diperoleh dari perpustakaan, dikumpulkan dari literatur, serta instansi lainnya yang terkait dengan topik penelitian, maupun browsing internet.

Metode analisis yang digunakan untuk mengetahui faktor-faktor yang mempengaruhi produksi susu kambing perah adalah model cobb douglas dengan rumus :

$\ln Y=\alpha_{0}+\beta_{1} \ln X_{1}+\beta_{2} \ln X_{2}$

Dimana:

$\ln \mathrm{Y}=$ Produksi susu kambing perah $\quad($ Liter/Hari $)$

$\alpha_{0} \quad=$ Konstanta

$\ln \mathrm{X}_{1}=$ Jumlah pemberian pakan hijauan kambing produksi $(\mathrm{Kg} / \mathrm{Hari})$

$\ln \mathrm{X}_{2}=$ Jumlah pemberian ampas tahu $(\mathrm{Kg} / \mathrm{Hari})$

$\beta_{1} \cdot \beta_{2}=$ Parameter

a. Uji F

Untuk menguji kebenaran hipotesis, maka dilakukan pengujian sebagai berikut :

$$
\mathrm{F}_{\text {hitung }}=\frac{R^{2} / k}{\left(1-R^{2}\right) /(n-k-1)}
$$


Dimana :

$\mathrm{R}^{2}=$ koefisien determinasi

$\mathrm{k}=$ Jumlah koefisien yang ditaksir

$\mathrm{n}$ = Banyaknya sampel

Uji " $F$ " digunakan untuk mengetahui bentuk hubungan secara serempak antara variabel bebas dengan variabel tak bebas (Sudjana, 2002).

Dengan Kaedah Keputusan :

- Jika F Hitung > F Tabel, maka Ho ditolak dan Ha diterima, berarti variabel bebas secara bersama-sama (Minimal salah satu ) berpengaruh terhadap variabel terikat.

- Jika F Hitung < F Tabel, maka Ho diterima dan Ha ditolak, berarti semua variabel bebas secara bersama-sama tidak berpengaruh nyata terhadap variabel terikat.

b. Uji t

Untuk melihat pengaruh secara parsial dilakukan analisis varian sebagai berikut (Sudjana, 2002).

$$
\mathrm{t}_{\mathrm{cari}}=\frac{a_{i}}{S E a_{i}}
$$

Dimana :

$a_{i}=$ Koefisien regresi variabel $X_{i}$

SEai $=$ Standar error dari koefisien regresi

Dengan kaedah keputusan :

- $\mathrm{t}_{\text {Hitung }}>\mathrm{t}_{\text {Tabel, }}$ pada taraf nyata 0,5 maka terima $\mathrm{H}_{\mathrm{a}}$ dan tolak $\mathrm{H}_{\mathrm{o}}$, artinya variabel-variabel bebas mempunyai pengaruh yang nyata (significant) terhadap variabel terikat.

- $\mathrm{t}_{\text {Hitung }}<\mathrm{t}_{\text {Tabel, }}$ pada taraf nyata 0,5 maka terima $\mathrm{H}_{\mathrm{o}}$ dan tolak $\mathrm{H}_{\mathrm{a}}$, artinya variabel-variabel bebas tidak berpengaruh nyata ( non significant) terhadap variabel terikat.

Dimana :

$\mathrm{H}_{\mathrm{o}}=$ Jumlah pemberian pakan hijauan $\left(\mathrm{X}_{1}\right)$ dan jumlah pemberian ampas tahu $\left(\mathrm{X}_{2}\right)$, tidak berpengaruh nyata terhadap produksi susu kambing yang dihasilkan pada usaha peternakan UD. Atjeh Livestock Farm.

$\mathrm{H}_{\mathrm{a}}=$ Jumlah pemberian pakan hijauan $\left(\mathrm{X}_{1}\right)$ dan jumlah pemberian ampas tahu $\left(\mathrm{X}_{2}\right)$, berpengaruh nyata terhadap produksi susu kambing yang dihasilkan pada usaha peternakan UD. Atjeh Livestock Farm.

\section{HASIL DAN PEMBAHASAN}

Berdasarkan Tabel dapat kita lihat bahwa dari jumlah pemberian pakan hijauan dan ampas tahu yang berbeda-beda di setiap kambing perah maka akan menghasilkan produksi susu yang berfluktuatif, namun semakin jumlah pemberian pakan hijauan dan ampas tahu ditingkatkan maka akan meningkatkan produksi susu kambing perah, seperti pada kambing ke 1 (satu ) jumlah hijauan yang diberikan sebesar $12 \mathrm{~kg}$, dan ampas tahu sebesar $20 \mathrm{~kg}$ hanya bisa menghasilkan susu sebanyak $4200 \mathrm{ml}$, sedangkan pada kambing 15 (lima belas) dengan pemberian pakan hijauan sebesar $40 \mathrm{~kg}$ dan ampas tahu sebesar $38 \mathrm{~kg}$ mampu memproduksi 
susu sebesar $5600 \mathrm{ml}$. Maka dari itu jumlah pemberian pakan hijauan dan ampas tahu sangat berpengaruh terhadap peningkatan produksi susu kambing perah.

Tabel 2. Pengaruh Pemberian Pakan Hijauan dan Ampas Tahu Terhadap Produksi Susu

\begin{tabular}{|c|c|c|c|}
\hline No & Produksi Susu & Hijauan & Ampas Tahu \\
\hline 1 & 4200 & 12 & 20 \\
\hline 2 & 4400 & 14 & 20 \\
\hline 3 & 4600 & 16 & 22 \\
\hline 4 & 4800 & 18 & 30 \\
\hline 5 & 5000 & 20 & 26 \\
\hline 6 & 5100 & 22 & 33 \\
\hline 7 & 5000 & 24 & 29 \\
\hline 8 & 5000 & 26 & 31 \\
\hline 9 & 5300 & 28 & 38 \\
\hline 10 & 5400 & 30 & 35 \\
\hline 11 & 5200 & 32 & 35 \\
\hline 12 & 5400 & 34 & 36 \\
\hline 13 & 5500 & 36 & 37 \\
\hline 14 & 5500 & 38 & 36 \\
\hline 15 & 5600 & 40 & 38 \\
\hline
\end{tabular}

Sumber : Data diolah, 2016

\section{Analisis Faktor-Faktor yang Mempengaruhi Produksi Susu Kambing}

\section{a. Uji Hipotesis Serempak (Uji F)}

Uji hipotesis secara serempak digunakan untuk mengetahui pengaruh dari Variabel Bebas secara keseluruhan terhadap Variabel Terikat.

Tabel 3. Uji Hipotesis Serempak

\begin{tabular}{|ll|c|c|c|c|c|}
\hline Model & & Sum of Squares & Df & Mean Square & F & Sig. \\
\hline 1 & Regression & .098 & 2 & .049 & 138.415 & $.000^{\mathrm{a}}$ \\
& Residual & .004 & 12 & .000 & &
\end{tabular}


a. Predictors: (Constant), LNAT, LNH

b. Dependent Variable: LNPS

Dari tabel di atas diperoleh nilai $F_{\text {hit }}=138.415$ sedangkan untuk $F_{\text {tabel }}=3.98$, karena nilai $\mathrm{F}_{\text {hit }}=138.415>\mathrm{F}_{\text {tabel }}=3.98$, maka kesimpulan yang dapat diambil adalah menolak $\mathrm{H}_{0}$. Artinya variabel hijauan dan ampas tahu secara bersama-sama berpengaruh nyata terhadap produksi susu kambing perah.

\section{b. Koefisien Determinasi}

Koefisien determinasi adalah besarnya keragaman (informasi) di dalam variabel $\mathrm{Y}$ yang dapat diberikan oleh model regresi yang didapatkan. Adapun hasil dari uji determinasi adalah sebagai berikut :

Tabel 4. Uji Determinasi

\begin{tabular}{|l|l|l|l|l|l|}
\hline Model & $\mathrm{R}$ & $\mathrm{R}$ Square & Adjusted R Square & $\begin{array}{l}\text { Std. Error of the } \\
\text { Estimate }\end{array}$ & Durbin-Watson \\
\hline 1 & $.979^{\mathrm{a}}$ & .958 & .952 & .01880 & 1.898 \\
\hline
\end{tabular}

a. Predictors: (Constant), LNAT, LNH

b. Dependent Variable: LNPS

Pada tabel Uji determinasi di atas diperoleh nilai $\mathrm{R}^{2}=0,952$, menyatakan bahwa $95 \%$ keragaman tingkat produksi susu disebabkan oleh jumlah hijauan dan ampas tahu selebihnya dipengaruhi oleh faktor lain yang tidak dimasukkan ke dalam model.

\section{c. Uji Hipotesis Parsial}

Uji hipotesis secara parsial digunakan untuk mengetahui pengaruh dari masing-masing Variabel Bebas terhadap Variabel Terikat.

Tabel 5. Uji Hipotesis Parsial

\begin{tabular}{|c|c|c|c|c|c|c|c|c|}
\hline \multirow{2}{*}{\multicolumn{2}{|c|}{ Model }} & \multicolumn{2}{|c|}{$\begin{array}{l}\text { Unstandardized } \\
\text { Coefficients }\end{array}$} & \multirow{2}{*}{$\begin{array}{l}\text { Standardized } \\
\text { Coefficients } \\
\text { Beta }\end{array}$} & \multirow[b]{2}{*}{$\mathrm{T}$} & \multirow[b]{2}{*}{ Sig. } & \multicolumn{2}{|c|}{ Collinearity Statistics } \\
\hline & & B & Std. Error & & & & Tolerance & VIF \\
\hline \multirow[t]{3}{*}{1} & (Constant) & 11.567 & .173 & & 66.931 & .000 & & \\
\hline & $\mathrm{LNH}\left(\mathrm{X}_{1}\right)$ & .145 & .036 & .638 & 4.016 & .002 & .137 & 7.278 \\
\hline & $\begin{array}{l}\text { LNAT } \\
\left(\mathrm{X}_{2}\right)\end{array}$ & .134 & .060 & .358 & 2.255 & .044 & .137 & 7.278 \\
\hline
\end{tabular}

a. Dependent Variable: LNPS

Dari Tabel $\boldsymbol{U}$ ji Parsial diatas dapat dibuat suatu persamaan regresi :

\section{LnPS = 11,567 + 0,145 $\ln H+0,134 \ln A T$}

Dari uji parsial diperoleh nilai variabel hijauan untuk $t_{\text {hitung }}=4,016$ sedangkan $t_{\text {tabelnya }}$ $=2,17881$ Begitu juga untuk variabel ampas tahu diperoleh nilai untuk $t_{\text {hitung }}=2,255$ sedangkan $t_{\text {tabelnya }}=2,17881$, karena nilai $t_{\text {hitung }}>t_{\text {tabel }}$ maka dapat diambil kesimpulan bahwa semua variabel menolak $\mathrm{H}_{0}$. Artinya variabel hijauan maupun ampas tahu mempunyai pengaruh nyata secara parsial terhadap produksi susu kambing perah.

\section{KESIMPULAN DAN SARAN}

Berdasarkan hasil penelitian maka dapat disimpulkan bahwa : Jumlah pemberian pakan hijauan dan ampas tahu berpengaruh terhadap produksi susu kambing perah. Dimana 
diperoleh nilai dari uji serempak untuk $\quad \mathrm{F}_{\text {hit }}=138.415$ sedangkan untuk $\mathrm{F}_{\text {tabel }}=3.98$, karena nilai $\mathrm{F}_{\text {hit }}=138.415>\mathrm{F}_{\text {tabel }}=3.98$, maka kesimpulan yang dapat diambil adalah menolak $\mathrm{H}_{0}$. Artinya variabel hijauan dan ampas tahu secara bersama - sama mempunyai pengaruh nyata terhadap produksi susu kambing perah, sedangkan dari uji parsial diperoleh nilai variabel hijauan untuk $\mathrm{t}_{\text {hitung }}=4,016$ sedangkan $\mathrm{t}_{\text {tabelnya }}=2,17881$, karena nilai $\mathrm{t}_{\text {hitung }}=4,016>\mathrm{t}_{\text {tabel }}=$ 2,17881, maka kesimpulan yang dapat diambil adalah menolak $\mathrm{H}_{0}$. Begitu juga untuk variabel ampas tahu diperoleh nilai untuk $t_{\text {hitung }}=2,255$ sedangkan $t_{\text {tabelnya }}=2,17881$, karena nilai $t_{\text {hitung }}=2,255>t_{\text {tabel }}=2,17881$, maka kesimpulan yang dapat diambil adalah menolak $\mathrm{H}_{0}$. Artinya variabel hijauan maupun ampas tahu mempunyai pengaruh nyata terhadap produksi susu kambing perah.

Adapun hasil dari analisis yang dilakukan dan kesimpulan maka saran yang diberikan yaitu, Diharapkan kepada peneliti selanjutnya untuk memasukkan variabel hijauan dan ampas tahu yang dapat menambah produksi susu kambing perah Peranakan Etawa (PE).

\section{DAFTAR PUSTAKA}

Dirjen Peternakan dan Kesehatan Hewan, 2014. Statistik Peternakan Aceh Besar. Badan Pusat Statistik. Aceh.

Juniar S. 2009. Pusat Penelitian dan Pengembangan Peternakan. Penebar Swadaya. Jakarta.

Setiawan, T. dan A. Tanius. 2005. Beternak Kambing Perah Peranakan Etawa. Penebar Swadaya. Jakarta.

Sudjana, 2002. Metode Statistika, Tarsito. Bandung.

Wolden, Janri HS.2009. Strategi Usaha Pengembangan Kambing Perah Pada PT. Caprito A.P Kecamatan Cariu Kabupaten Bogor. Skripsi. Fakultas Pertanian, Institut Pertanian Bogor. 